\title{
DETERMINANTS OF STUDENTS' SATISFACTION WITH DISTANCE EDUCATION PROGRAMS AT HO CHI MINH CITY OPEN UNIVERSITY
}

\author{
Nguyen Van Phuc, Rector of HCMC Open Univeristy, \\ Email: nvphuc@vahoo.com
}

\author{
Nguyen Minh Duc, Vice Director, the Center for Development Studies \\ (HCMC Open University), Email: nguvenminhducts@gmail.com
}

\begin{abstract}
This study was implemented to identify factors affecting students'satisfaction with the distance learning programs offered by Ho Chi Minh City Open University. A system of econometric equations was simultaneously regressed by SUR procedure in SAS program with dependent variables representing three components of students'satisfaction with instructors, their satisfaction with curriculums and their satisfaction with program administration. Data for the regression were collected from a survey in two years 2009 and 2010 with structured questionnaires responded by 361 students following distance learning programs in five majors: Business Administration, Economics, Finance, Sociology and Construction. The regression results confirmed that there existed positive interrelationship among students'satisfaction with the three components. A diagram was constructed to exhibit magnitude of the interrelationship as well as determinants of students'satisfaction with each component. Besides the interrelationship, the satisfaction for instructors was significantly determined by other factors such as age, marital status, communication (directly or indirectly) with instructors. Whilst, other factors affecting students' satisfaction with distance learning curriculums include the frequency of students' Internet use and their income.
\end{abstract}

Keywords: student, satisfaction, distance learning, Seemingly Unrelated Regression, curriculum.

\section{INTRODUCTION}

Characterized by no direct faceto-face contact between students and instructors in class meetings, Distance Education benefits students through the well planned curriculum and appropriate guidance from teachers (Holmberg, 1996). In Vietnam, distance learning is considered non-formal education since the interaction between teachers and learners is not regular (Thiep, 2009). Along with in-service training, distance education has advantages toward learners such as lower cost, flexible studying time, no entry exam requirement, and recognized degree. Under rapid development of Internet applications in Vietnam, the distance education has involved more and more students enrolling into its programs. The country recently has more than 15 institutions offering distance learning programs, enrolling more than 198,000 students in various majors: information technology, English, business administration, economics, 
constructions,... Along with Hanoi Open University, Ho Chi Minh City Open University (HCMCOU) is one of two first universities in Vietnam offering distance education programs to create more learning opportunities for learners who desire to follow higher education but do not have enough time and capacity to enroll into full-time programs. Since 1993, the university has expanded to nine training programs with 12 majors. After almost twenty years of the development, it is necessary to assess quality of training programs of distance education. The first and most important factor to measure the quality is satisfaction of learners with their learning programs. Not only relating to success after graduation (Chen and Hughes, 2004), learners' satisfaction may be used to describe education effectiveness and support the improvement process of education quality (Scott et al., 2008). Phuc and Hong (2011) also measure students' satisfaction with the distance learning programs offered by Ho Chi Minh City Open University through with three components of their satisfaction. The components are satisfaction with curriculums (including curriculum content, learning materials, curriculum structures, course content), satisfaction with instructors (qualification, dedication, enthusiasm, communication skills, teaching methods) and satisfaction with program administration (administrative protocols, responsibility and enthusiasm of university staff, responsibility and enthusiasm of satellite training centers' staff, seriously examination, exam score release). However, the above study was yet to identify factors affect students' satisfaction with the program. This study was implemented not only to identify factors affect students' satisfaction with the program but also to explore interrelationship between students' satisfaction with the three components.

\section{Research methodology}

According to Chen and Hughes (2004), various researches on students' satisfaction during last decades has employed many statistical methods to examine relationship between students' experience in studying time and their satisfaction with components of training programs and supporting services. The methods include descriptive statistics, linear regression and multi-level analysis (e.g. Umbach and Porter, 2001), ordinal logistic regression (e.g. Chen and Hughes, 2004), exploratory and confirmatory factor analysis (e.g. Fredericksen et al., 2006, Duy, 2007).

Factors affecting students' satisfaction have been also identified in previous research. Those are instructors' quality (Fredericksen et al., 2006, Powell, 2007), teaching effectiveness (Johnson et al., 1999), communication between instructors and learners, instructors' advising capacity, and course number (Arbaugh, 2001), course content (Zarghami and Hausafus, 2002), learning environment, learning material supply (Northrup, 2002). Learning community, team working and technological capacity of students are also found relating to their satisfaction (Johnson et al., 2000). OrtizRodriques, et. al (2005) found that student satisfaction with online courses was linked to communication and timely feedback, good course design with rich media for course materials, administrative issues including good software, and support service. Wyatt (2005) determined that over half $(54 \%)$ of students surveyed felt that good interactions between students and with the instructor were important factors for student satisfaction. According to Hermans et al. (2009) using Internet and its applications such as email, chat room, instant messaging, and discussion forums provides more opportunities for interaction 
between instructors and students, leading to more satisfaction of students who had followed an online course.. Evans (2009) found the following factors related to student satisfaction: faculty involvement, curriculum, and student engagement. For the distance learning programs offered by Ho Chi Minh City Open University, a previous study by Phuc and Hong (2011) measured students' satisfaction with three components of the program. Those are curriculums (including curriculum content, learning materials, curriculum structures, course content), instructors (qualification, dedication, enthusiasm, communication skills, teaching methods) and program administration (administrative protocols, responsibility and enthusiasm of university staff, responsibility and enthusiasm of satellite training centers' staff, seriousness in examination, exam score release). In a study of students' satisfaction with an online course, Hermans et al. (2009) also found interrelationship between students' satisfaction with instructors, satisfaction with school services and their satisfaction with the course. From the theorical findings from above authors, especially from the recent study of Phuc and Hong (2011), an empirical framework (Figure 1) was designed for multiple regressions to identify factors factors affect students' satisfaction with the program as well as interrelationship between students' satisfaction with the three components of the program.

In this study, besides descriptive statistics analysis, a system of econometric equations was simultaneously regressed by Seemingly Unrelated Regression (SUR) procedure with support from SAS programming to identify interrelationship between students' satisfaction with three components of distance learning program and explore some factors affecting the satisfaction with each component. SUR (seemingly unrelated regression) is a linear regression method for a system of equations which gives separate estimation results. SUR can correct interrelationship between dependent and exogenous variables and correct interrelationship between explanatory variables and errors in each regressing equation. Dependent variables are students' satisfaction with instructors, their satisfaction with curriculum and lectures' contents and their satisfaction with program administration. The satisfaction was measured by the 5-point Likert scale. Explanatory variables in estimated equations are students' characteristics and efforts as exhibited in Figure 1. 
Figure 1. Empirical framework for regression analysis

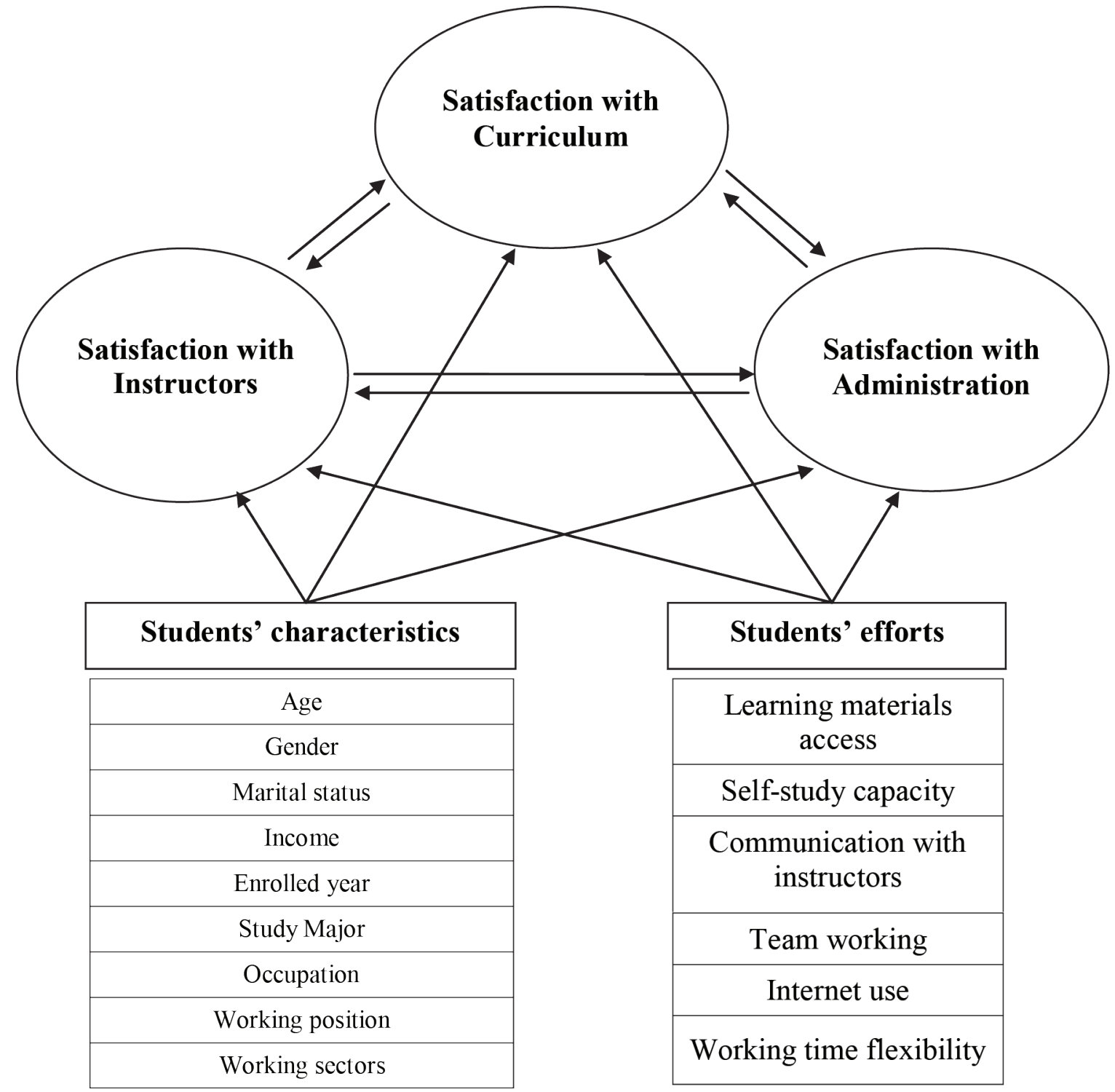

Data were collected from a survey in two years 2009-2010 with 500 structured questionnaires sent randomly to students' houses and reminded/explained by telephone. Respondents in this study are students enrolling to distance learning program of the university into five majors: Business Administration, Economics and Laws, Finance-Banking-Accounting, Sociology and Construction. Out of the 500 questionnaires sent out, 361 answered questionnaires had returned to investigators.

\section{Results and discussion}

\section{Information on respondents} With $54.67 \%$ of male students, in their working institutions/corporates.

among 361 respondents, 33.53\% majored in Business Management, $21.97 \%$ in Construction Engineering, 20.52\% in Economics and Laws, $16.47 \%$ in Finance-Banking-Accounting and 7.51\% in Sociology. Except 15 respondents unemployed, number of learners working in private business sector $(49.25 \%)$ is more than that in state sector (46.27\%) and most of them working in fixed working time $(80 \%)$. Occupation of the learners is diverse, varying from workers, officials (cover more than $80 \%$ of respondents) to businessmen or even undergraduate students of other universities. 15.41\% respondents hold management positions 
Monthly income of distance education learners is mostly in the range of $1.5-4.0$ million dongs (75 - 200USD), with the percentage of high income ( $>8$ million dong) is only $4 \%$ of respondents. This low average income may be explained by rather young age of the learners with $62 \%$ younger than 30 years old and $22 \%$ in $30-$ 40 ages while $51 \%$ respondents are single.

Students' Satisfactions with Three Components of Distance Education Program at HCMC Open University

Interrelationship of students' satisfaction with three components

To explore an interrelationship between students' satisfaction with three components of distance learning program at HCMC Open University, an equation system is estimated by SUR regression in which dependent variables are the satisfaction with each component: curriculum, instructors and administrative services. Values of dependent variables are average scores of internal items in each component. The regression shows that level of students' satisfaction with one component would give positive and significant effect $(\mathrm{P}<0.01)$ on the satisfaction with other components (Figure 2). Students who are satisfied with their instructors would be also satisfied with curriculum and administrative services of the distance education programs, and reverse. In Figure 2, the numbers are coefficients estimated by the equation system regression. In the interrelation, effects of students' satisfaction with curriculum and with instructors on their satisfaction with administrative services ( 0.25 and 0.49 , respectively) would be larger than the reverse ones $(0.19$ and 0.38 , respectively). Whilst, the effect of students' satisfaction with curriculum on the satisfaction with instructors is significant $(\mathrm{P}<0.05)$ and estimated to be equal to the reverse effect $(0.39)$.

Figure 2. Interrelationship between students' satisfaction with three components and their determinants

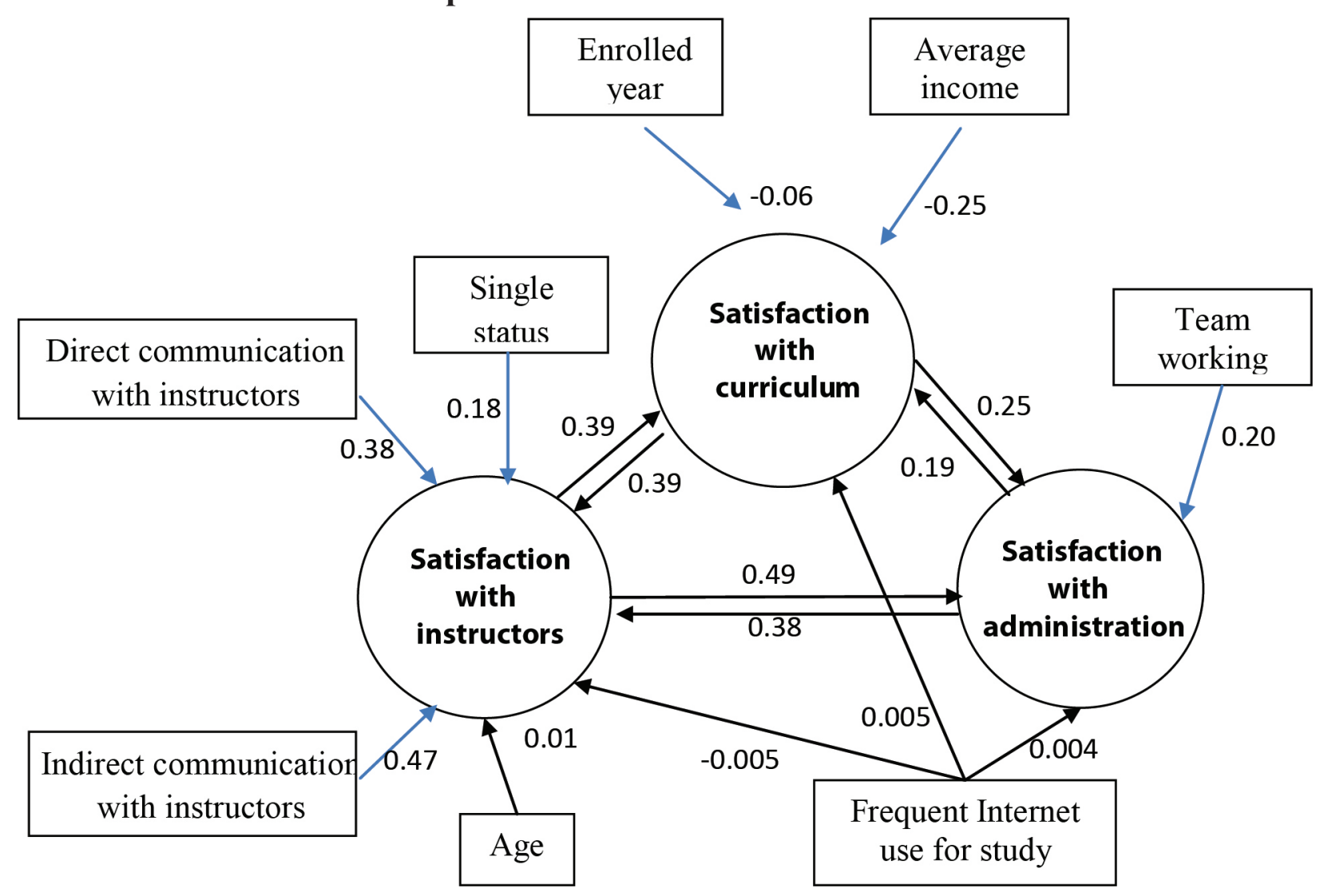


Students'satisfaction with instructors

Distance learning allows students to be more active in time and space of their studying but it also requires instructors to get more appropriate skill and methods of their teaching for this kind of education in comparison of those of regular and fulltime education. In distance education, because face-to-face interaction between instructors and students is limited, instructors have to play the role of supporters, guiders to help students in their progress of knowledge achievement. Students' satisfaction with instructors was measured by 5-point Likert scale with 5 internal items (scored variables) of instructors' enthusiasm, knowledge, teaching skills, seriously instruction and teaching methods perceived by learners enrolling into distance education programs offered by HCMC Open University. Percentage of respondents satisfying with instructors is described in Figure 3.

Figure 3. Students' satisfaction with instructors of distance education programs

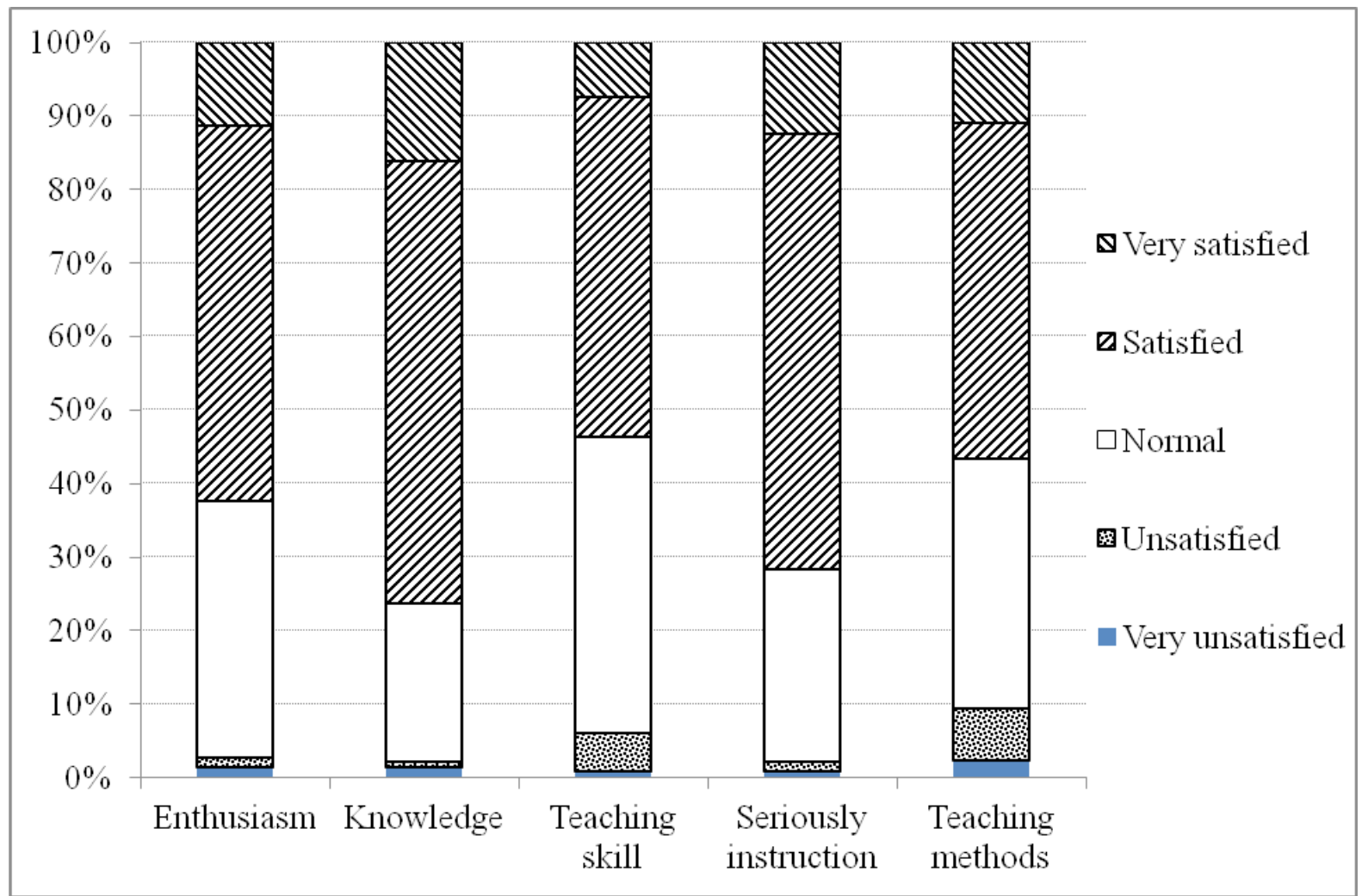

Under SUR regression (Figure 2), working sector, working time flexibility, the older learners are estimated to be more satisfied with instructors in comparison with younger ones $(\mathrm{P}<0.1)$. This observation is due to the fact that the elder has more experience in social life and more satisfaction with life (Frank, 2005) so that they seem to have more satisfaction with instructors than the younger. However, this effect is not so large; the elders seems to be more satisfied by $1 \%$ relative to the youngers. Other various variables representing learners' characteristics, such as working position, occupation, income, learning material, searching capacity, have no significant effect on their satisfaction with instructors of distance education programs offered by the HCMC Open University under SUR regression but learners' marital status. A single learner is estimated to satisfy with instructors rather than a married one by $18 \%$ at significant level of $95 \%$. Married learners seem to get more troubles in time arrangement for their own family and for studying so that they may rely more on instructors. 
Students who spend more time in the Internet use for their distance learning are estimated to be less satisfied with their instructors $(\mathrm{P}<0.01)$. This interesting finding can be explained by an argument that as students use Internet frequently, they may improve their self-study capacity to achieve more knowledge from online resources, their dependence on instructors to get knowledge would be lessened, and they require more qualification from instructors. However, communication between instructors and students is very important to create satisfaction to students of distance education programs. Usually, in each course subject, instructors can meet learners during 2-4 review classes or online meetings. After the review classes, learners would self-study to prepare for their final examination and they often contact with instructors directly (in class review or via telephone) or indirectly (via email, chat room,...). The SUR regression in this study justified that the communication, directly or indirectly, would create more satisfaction with instructors $(\mathrm{P}<0.01)$.

Students'satisfaction with curriculum

According to Chen and Hughes (2004) students' experience during studying progress is relating to their satisfaction. Besides instructors' qualification and pedagogical skills, curriculum quality and course organization along with course content determine the effectiveness of a distance program innovation (Brown,
2001). The learners' satisfaction on curriculum of the distance education program offered by HCMC Open University was measured by the 5-point Likert scale from "very satisfied" to "very unsatisfied" and expressed in Figure 4 with 4 internal items of "Curriculum content", "Learning materials", "Curriculum structure" and "Course content". The "Curriculum content" implies quantity and title of courses included in curriculum while "curriculum structure" mentions sequence and relative credit numbers of the courses.

WithSUR regression, almostvariables regarding students' characteristics did not affect significantly on their satisfaction with distance education curriculum offered by the HCMC Open University. The higher satisfaction levels were expressed by students spending more time in Internet use for their study $(\mathrm{P}<0.05)$. However, the number of years enrolled into distance learning programs gives a negative effect on the satisfaction $(\mathrm{P}<0.1)$. The longer following distance learning program, the less satisfaction students perceive. The decrease in satisfaction along with duration involving in distance education seems to be consistent with the diminishing law of marginal utility in economics. The regression also shows that students having average income (4-8 million dong/month) express less satisfaction than lower or high income students $(\mathrm{P}<0.1)$. 
Figure 4: Students' satisfaction with curriculum of distance education program in HCMC Open University

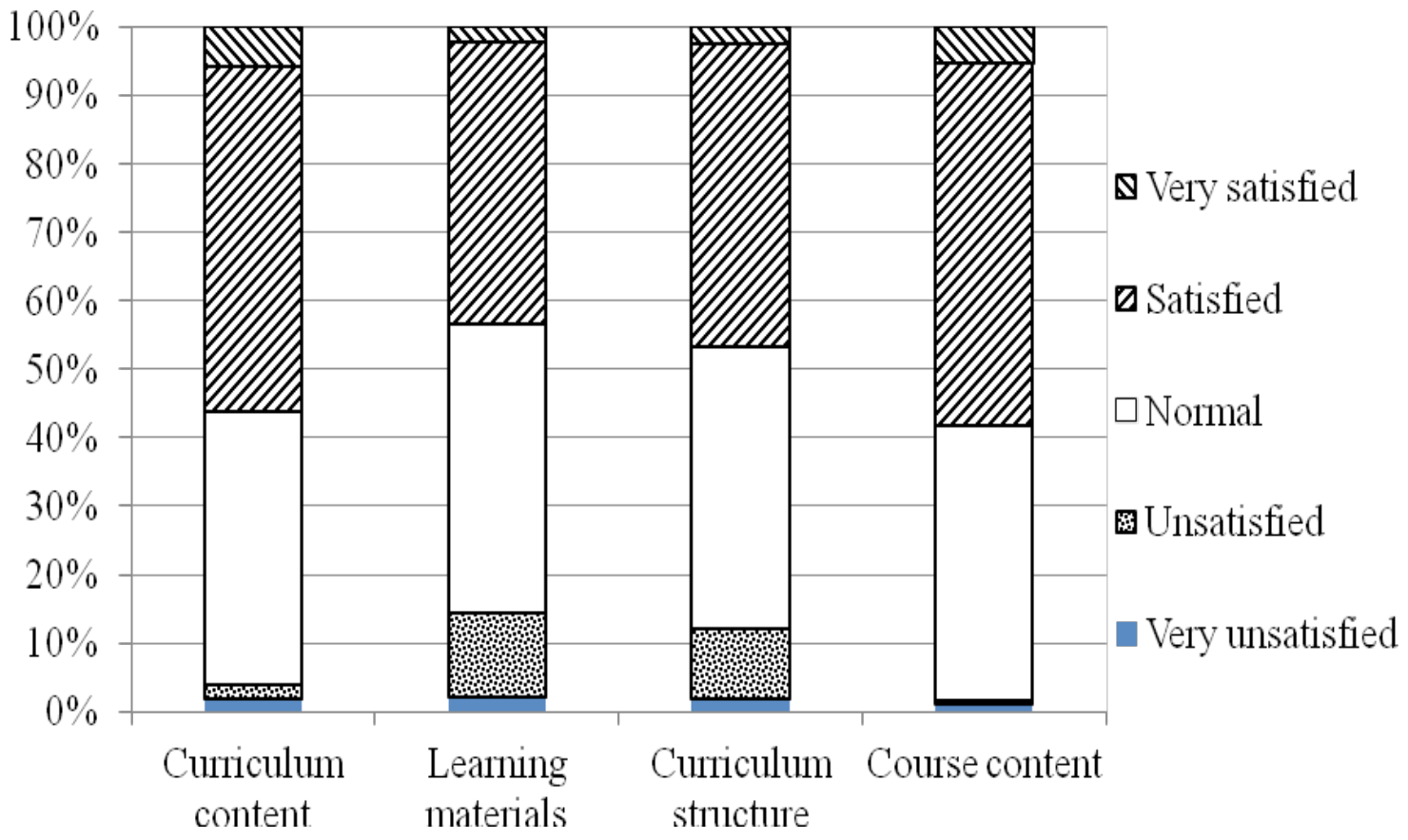

Students' satisfaction with program administrative services

Besides advantages from technological innovation and development (Kane, 2004), students of distance education programs still face troubles in their study such as time constraints (Scott, 2008). They need appropriate support to assist them to develop studying skills and achieve success in their studying progress (Pannekoek, 2008). Internal items used to measure students' satisfaction with administration of distance education programs at HCMC Open University included administrative protocols, responsibility and enthusiasm of administrative staff, based in the head office of the university or at its satellite training centers, seriousness in examination and exam score release (Figure 5).

With the regression results (Figure 2 ), the students studying in groups with team working spirit were estimated to be more satisfied with administrative services from the HCMC Open University $(\mathrm{P}<0.1)$ relative to the ones studying alone. Team working allows them to build community relationship or social networks, and from that, they achieve updated information and knowledge easier than the ones studying alone. This result is consistent with a previous finding by Sampson et al. (2010) which identified a positive effect of relationship in study community on satisfaction of students joining online classes. Positive effect of Internet time spending for studying on program administration was also confirmed by the regression. The students who use Internet frequently for their study may receive more support from administrators of distance training programs via online communication, thus they have more satisfaction with the administrative support. 
Figure 5. Students' satisfaction with program administration in distance education programs at HCMC Open University

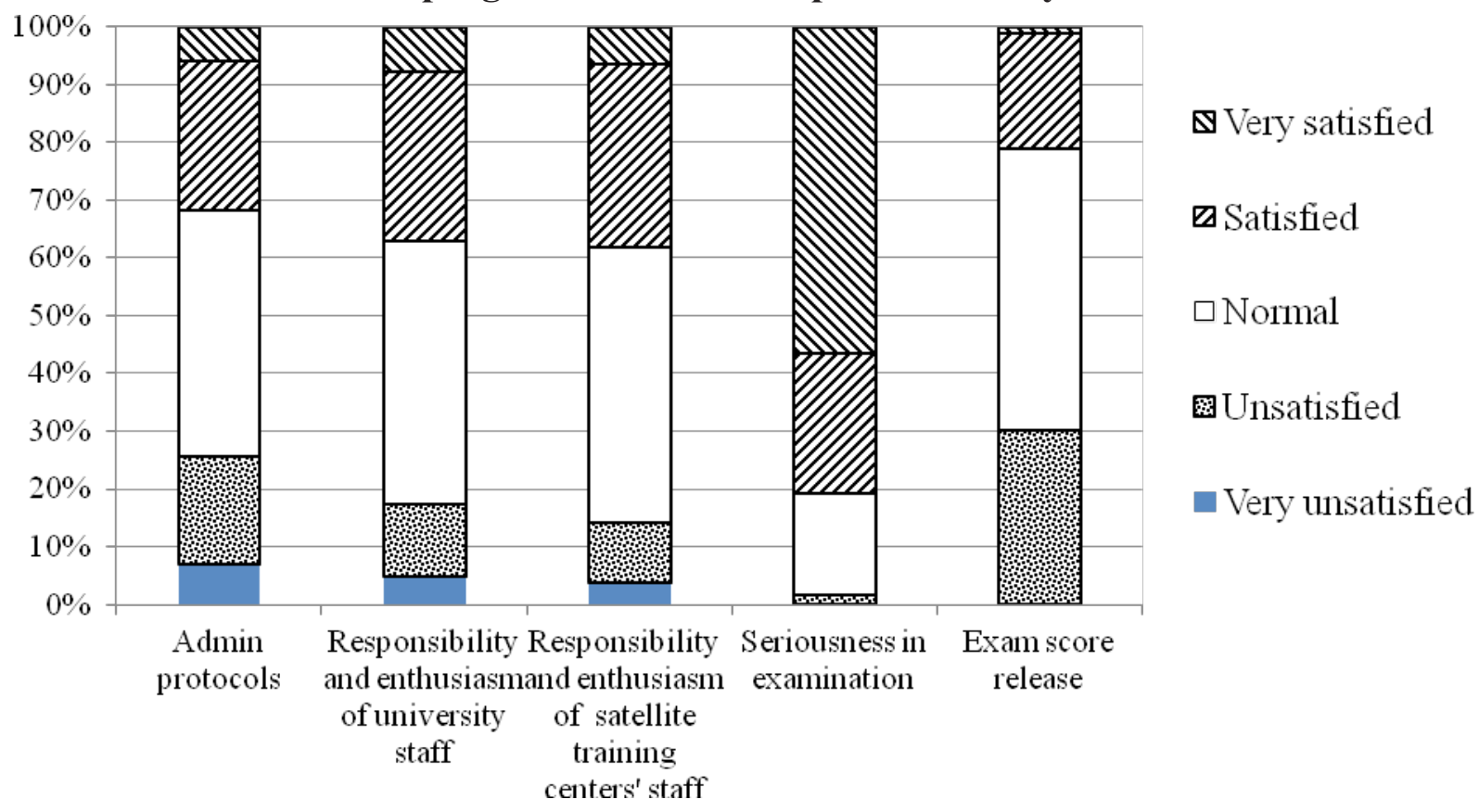

\section{CONCLUSION}

The SUR regression results confirm that there exists positive interrelationship between students' satisfactions with three components (instructors, curriculum, and administration) of distance education programs offered by the HCMC Open University. Students who are satisfied with their instructors would also be satisfied with curriculum and administrative services of the distance education programs, and reversely. Frequently using Internet would improve students' satisfaction with curriculum and administrative services but lessen their satisfaction with instructors. Besides the interrelationship, the satisfaction for instructors was significantly determined by other factors such as students' age, marital status, communication (directly or indirectly) with instructors. While team working capacity of students affects positively on their satisfaction with the program administration, other factors affecting students' satisfaction with distance learning curriculums are the year students enrolled into their learning program, and their income.

The above findings imply some recommendations to the Directorate Board of the HCMC Open University and Managers of the Distance Education Program of HCMC Open University. The Program should promote more frequent using Internet (via university forums, websites, emails, or social networks) in course delivery and communication between instructors and learners. Using Internet also encourages learners to build their networks and to enhance their team working capacity; from that eventually, their satisfaction with the Program is increasing. Instructors of distance education programs, then, have to improve their qualifications and teaching skills to meet the increasing requirements from learners. 


\section{REFERENCES}

Arbaugh, J.B., (2001). "How Instructor Immediacy Behaviors Affect Student Satisfaction and Learning in Web-Based Courses", Business Communication Quarterly 2001, 64(4): 42-54

Brown, R.E., (2001). "The Process of Community-Building In Distance Learning Classes".Journal of Asynchronous Learningh Network. 5(2): 18-35

Chen, C-K and Hughes, J., (2004). “Using Ordinal Regression Model to Analyze Student Satisfaction Questionnaires”.Association for Institutional Research, Volume 1.

Duy, N.K. (2007). “A Study on Students' Satisfaction with Training Quality of Master Programs at the Hochiminh City University of Economics". The Hochiminh City University of Economics, Vietnam.

Evans, T. N. (2009). An investigative study of factors that influence the retention rates in online programs at selected state, state-affiliated, and private universities. Doctoral dissertation. Robert Morris University. AAT 3388741.

Frank, R.H., (2005). Does absolute income matter? In: P. L. Porta and L. Bruni (editors.), Economics and Happiness, Oxford University Press,

Fredericksen E., Pickett, A., Shea, P., Pelz, W. and Swan, K., (2006). "Student Satisfaction and Perceived Learning with On-line Courses: Principles and Examples from the SUNY Learning Network", UR Research University of Rochester (www.aln.org/ publications/jaln/v4n2/pdf/v4n2 fredericksen.pdf)

Hermans, C. M., Haytko, D. L. and Mott-Stenerson, B. (2009). Student Satisfaction in Web-enhanced Learning Environments, Journal of Instructional Pedagogies, Vol. 1: $82-100$.

Holmberg, B. (1996). "On the Potential of Distance Education in the Age of Information Technology". Journal of Universal Computer Science, 2(6): 484-491

Johnson, S., Aragon, S. R., Shaik, N., and Palma-Rivas, N., (2000).“Comparative Analysis of Learner Satisfaction and Learning Outcomes in Online and Face-toFace Learning Environments".Journal of Interactive Learning Research, 11(1): $29-49$

Kane, K. (2004). Quality matters: Inter-institutional quality assurance in online learning. Perspectives in Quality Online Education, Sloan-C View, 3(11):1-3.

Northrup, P, (2002). "A Framework for Designing Interactivity into Web-based Instruction". In: The ASTD E-Learning Handbook-Best Practices, Strategies, and Case Studies for an Emerging Field (Edited by A. Rossett), The McDraw-Hill Companies, Inc., New York. USA, p.127-137

Ortiz-Rodriquez, M., Teig, R; Irani, T., Roberts, T. G. , \& Rhoades, E. (2005). College students' perceptions of quality in distance learning. The Quarterly Review of Distance Education, 6(2), 97-105.

Pannekoek, F., (2008). Trends, Innovations, and Opportunities in Open and Distance Learning. The Global Forum on Open Distance Learning, Shanghai, 2008

Phuc, N.V. and Hong, T.T.K. (2011). An Investigation of Students' Satisfaction with the Distance Learning Program at Hochiminh City Open University. Journal of Science. HCMC Open University, 3(21):85-95. 
Powell, D. C., (2007). Student Satisfaction with a Distance Learning MPA Program: A Preliminary Comparison of On-Campus and Distance Learning Student Satisfaction with MPA Courses. MERLOT Journal of Online Learning and Teaching, 3(1)

Sampson, P.M., Leonard, J., Ballenger, J.W., and Coleman, J. C. 2010. Student Satisfaction of Online Courses for Educational Leadership. Online Journal of Distance Learning Administration, University of West Georgia, 8(3)

Scott, G. et al. (2008). Using Qualitative Data to Prove and Improve Quality in Australian Higher Education, University of Western Sydney, Sydney, Australia

Thiep, L.Q. (2009). Contribution of Distance Education to Higher Education System in Vietnam in Recent Decades, Proceedings of National Conference on Distance Education, The Globe Publishers, Nhà Xuất Bản Thế Giới, Hà Nội.

Umbach, P. D. and Porter, S. R., (2000). Academic Departments Impact Student Satisfaction? Understanding the Contextual Effects of Departments. Paper presented at the 41st Forum of the Association for Institutional Research, California, 2000

Wyatt, G. (2005). Satisfaction, academic rigor and interaction: Perceptions of online instruction. Educational Researcher, 125(3), 460-468.

Zarghami, F. and Hausafus, C.O., (2002). Graduate student satisfaction with interactive televised courses based on the site of participation. Quarterly Review of Distance Education, 3(3): 295-306. 